\title{
EL MAESTRO-ARQUITECTO JAN KRAUS S.J. EN EL RÍO DE LA PLATA
}

\author{
Carlos A. Page \\ Consejo Superior de Investigaciones Científicas y Técnicas (Argentina)
}

\begin{abstract}
El presente trabajo de carácter biográfico aborda la figura del coadjutor jesuita checo, Jan Kraus, que trabajó en la Provincia del Paraguay entre 1698 y 1714. Lo hizo en las reducciones de guaraníes, al igual que en las ciudades de Buenos Aires y Córdoba. En esta última, sede de la provincia, en edifícios como la Universidad, el Convictorio y el Noviciado. En algunos casos es complejo determinar su participación en diversas etapas de los mismos, ya que se destinaban a ellos muchos años de esfuerzo, en los que intervenían variados coadjutores, sobre todo alemanes e italianos. No todos los edificios se han conservado, en algunos casos fueron demolidos, en otros se mantienen sectores, conformando un conjunto de variados ámbitos, hoy en gran parte declarados Patrimonio de la Humanidad por la UNESCO.
\end{abstract}

Palabras clave: Misiones jesuíticas; Provincia Jesuítica del Paraguay; Jesuitas checos; Jan Kraus.

\section{THE MASTER-ARCHITECT JAN KRAUS S.J. IN RÍO DE LA PLATA}

This study deals with the biography of the Czech Jesuit coadjutor, Jan Kraus, who worked in the Province of Paraguay between 1698 and 1714. He was active in the Guarani reservations, as well as in the cities of Buenos Aires and Cordoba. In the latter he was involved in buildings such as the University, the Convictorio and Novitiate. In some cases it is difficult to determine his participation in the different stages of their construction, as it was carried out over long periods with the intervention of many coadjutors, especially Germans and Italians. Not all of these buildings have been preserved: in some cases they were demolished, but in others sections remain. Today they compose a varied group, now largely declared World Heritage Sites by UNESCO.

Key words: Jesuit Missions; Jesuit Province of Paraguay; Czech Jesuit; Jan Kraus.

\section{Introducción a las fuentes}

Las fuentes son relativamente escasas, algunas menciones en los catálogos trienales y en los secretos de la Compañía de Jesús, tanto de Paraguay como de Alemania Superior. Un escueto texto necrológico en las Cartas Anuas y referencias en otros documentos del Archivo General de la Nación Argentina. El Archivo de Indias conserva documentación de su viaje y hasta la descripción de su aspecto, publicado por el P. Pastells. 
La bibliografía no es nueva, pues de sus contemporáneos, el P. Antonio Sepp lo recordó con benevolencia. En cuanto a sus biógrafos se dividen entre europeos y argentinos, comenzando con el jesuita suizo Huonder, quien escribió por primera vez sobre el personaje ${ }^{1}$. Últimamente lo hicieron los checos Kalista y Ryneš, además de los alemanes Grulich y Gretenkord ${ }^{2}$, aunque como meros catálogos, extendiéndose un poco más Stěpánek ${ }^{3}$. En Argentina comenzaron los jesuitas Leonhardt y Furlong ${ }^{4}$, y profundizó este último ${ }^{5}$, siguiéndole paralelamente el historiador laico Sierra, y el arquitecto Buschiazzo ${ }^{6}$, al tratar en detalle la obra de la iglesia de Buenos Aires, agotando los aportes a su biografía. Pero indudablemente son más, y llegan a ser innumerables, los trabajos que tratan sobre el coadjutor checo, siguiendo a sus antecesores y agregando alguna opinión crítica a su obra. Entre ellos se destacan los arquitectos Giura, De Paula, Levinton y Sustersic ${ }^{7}$.

En el presente trabajo pretendemos sumar algún aporte y sobre todo volver al tema, tanto biográfico como desde la visión crítica de la arquitectura histórica, que a nuestro entender se subordina a la vida y personalidad de los hombres del pasado.

\section{La Alemania del Siglo XVII y los jesuitas}

La geografía de Alemania ha variado notablemente a lo largo de la historia, tanto en lo político como en la organización de la Compañía de Jesús. Luego del paso del beato francés Pedro Fabro por 1541 consolidaron el establecimiento del Instituto Claudio Jayo, Alfonso Salmerón y San Pedro Canisio, gracias al plan del procatólico Fernando I (1558-1564). En Viena lo hicieron en 1554 y dos años después en Ingolstadt y Praga en Bohemia, donde fundaron el colegio de San Clemente, bajo la dirección del P. Ursmar Goisson de Beaumont, con su noviciado (1573) y convictorio (1560). Luego se crearon los colegios de Olomouc/Olmütz (1566), Krumlov/Krumau (1585), Chomutov/Komotau (1591) y Kladsko/Glatz (1597).

El P. Canisio, que quedó en Baviera, fue el primer provincial de la flamante Provincia de Alemania Superior, creada en 1556. Abarcaba el sur de Alemania, Austria y Bohemia. Siete años después los colegios de Praga y de Viena pasaron a la nueva provincia austriaca, creada en 1563 y donde incluyeron Bohemia, designada provincia en 1623 bajo la dirección del P. Gergely Rumer $^{8}$. Pero antes de ello comenzó la Guerra de los Treinta Años (1618-1648) y los jesuitas fueron expulsados con la confiscación de sus bienes, regresando al poco tiempo.

En 1616 el general Mucio Vitelleschi (1615-1645), autorizó la partida del primer contingente de jesuitas de Alemania Superior a la América española ${ }^{9}$. Solo eran cuatro del colegio de Ingolstadt, sobre un total de 40 pedidos o indipetas. Tres para el Perú y uno, llamado Andrés Feldman (Agrícola), oriundo de Engen (Alemania), para el Paraguay. Viajaron con el procurador P. Juan de Viana, que contó además con miembros de la provincia Galo-Belga y Flandro-Belga ${ }^{10}$. Pocos lo

\footnotetext{
1 HuONDER, 1899.

2 Kalista, 1968. Ryneš, 1971. Grulich, 1981. Gretenkord, 1993.

3 STĚPÁNEK, 1979 y 1982.

${ }^{4}$ LeONHARDT Y Furlong, 1921.

5 FURLONG, 1944 y 1954.

6 Sierra, 1941. Buschiazzo, 1939 y 1960.

7 Giura, 1941. De Paula, 1997. Levinton, 1998 y 2012. Sustersic, 1999.

8 O’Neill y Domínguez, 2001: 51 y 783.

9 Sin embargo el primer jesuita de origen alemán que llegó al Nuevo Mundo fue el H. Pedro de Gouveia (el nombre alemán se desconoce), quien antes de 1598 estuvo al frente de la aldea de San Bernabé, dependiente del Colegio de Río de Janeiro (SiERra, 1941: 67).

10 Page, 2008: 504.
} 
hicieron luego, debido al conflicto bélico mencionado y sobre todo porque las autoridades hispanas no otorgaron licencias. De hecho hasta en 1651 se intentó que regresaran todos los jesuitas extranjeros del Paraguay. Pero los ignacianos lograron la Real Cédula de 1666 que permitió que un cuarto del número total de misioneros fueran extranjeros, extendiéndose a un tercio en 1674.

Jesuitas del centro-este del imperio (primero Alemán, luego Austríaco) del reino de Bohemia, es decir la actual República Checa, contaban con profunda formación teológica y doctrinal, destacándose a su vez como arquitectos, alarifes, boticarios, músicos, como el arquitecto novohispano Simón de Castro o Juan Roehr ${ }^{11}$.

El P. Storni contabiliza un total de 42 miembros de Alemania Superior ingresados a la Provincia del Paraguay, donde ubica al H. Kraus. Y cuando propone una división por países sitúa a Checoslovaquia (actual República Checa) en tres regiones: Bohemia con 18 jesuitas, Moravia con 6 y Eslovaquia con 3.

Al contrario de lo que se ha escrito sobre los jesuitas germanos, la amplia mayoría de los de Bohemia eran sacerdotes. Efectivamente entre 1681 y 1755 llegaron catorce sacerdotes y cuatro coadjutores. De ellos solo cuatro, incluyendo al H. Kraus, vinieron en el Siglo XVII y catorce en el XVIII. En esta última centuria 2 vinieron en la expedición de 1723, 3 en las de 1734, 1749 y 1755, solo 1 en la de 1747 y ninguno en la de 1755 en que llegaron alemanes de otras regiones.

El primer bohemio llegado al Paraguay fue el P. Wenseslao Alejo Christman (1648-1728) de Praga, misionero entre guaraníes que arribó a Buenos Aires en 1681 en la expedición del P. Tomás Donvidas. El resto partieron desde distintas ciudades, excepto 3 de Praga, sumándose al P. Christman, los PP. Juan Oppitz (1691-1739) que estuvo en Chile y Carlos Przikril (1718-1785), destinado al Paraguay pero que no alcanzó a viajar.

Las misiones de guaraníes fueron los mayores destinos, habiendo 8 jesuitas, además de 1 en chiquitos de gran notoriedad como fue el P. Juan José Messner (1703-1769) de Aussig/Ústí nad Labem, quien después de la expulsión murió en Perú; y uno entre los abipones del Chaco de amplia trayectoria, el P. Martín Dobrizhoffer (1718-1791) de Frymburk, conocido por su notable obra literaria.

Finalmente fueron también misioneros entre guaraníes los PP. Enrique Kordule (1658-1727) de Bestvina, Juan John (1655-1702) de Jaromer, que llegaron juntos en 1691 en la expedición del P. Antonio Parra, y el P. Francisco Juan Prockwedl (1701-1744) de Leitmeritz, además del coadjutor Wenseslao Horsky (1723-1791) de Königgrätz ${ }^{12}$.

\section{Desde Plzeň /Pilsen a la "Tierra sin Mal"}

Este era el contexto en que nacía en Plzeň/Pilsen, Bohemia (hoy República Checa) (fig. 1), el futuro coadjutor Jan Kraus, el 10 de junio $1660^{13}$. No hay precisiones certeras en cuanto a la fecha de nacimiento, pues después de las dos Guerras Mundiales, se perdieron los registros parroquiales.

\footnotetext{
11 STĚPÁNEK, 1987: 19-36; 2000: 205.

12 Furlong, 1978. Storni, 1980. Page, 2007.

13 Huonder, 1899: 145. Este autor da como fecha alternativa la del 7 de setiembre de 1659, siguiendo el Catálogo de Germania Superior como lo hace STORNI (1980: 155). Pero es posible que el jesuita suizo haya tenido acceso a su hoy desaparecida partida de bautismo, aunque quizás se refiera al Catálogo del Paraguay de 1710 que coincide con la primera fecha (Catálogo Trienal 1669-1677. ARSI, Paraq. 4-2, f. 489v.). En cambio en otros como el de 1710 da como fecha de nacimiento la de 8 de octubre de 1653, con la también inverosímil fecha de ingreso al Instituto del 27 de octubre de 1677 (Catálogo Trienal 1703-1762. ARSI, Paraq 6, f.40). LeOnhardT y FurLong (1921: 127) dan el 10 de junio de 1664 sin citar fuente.
}

Arch. esp. arte, LXXXVII, 347, JULIO-SEPTIEMBRE 2014, 245-262

ISSN: 0004-0428, eISSN: 1988-8511, doi: 10.3989/aearte.2014.16 


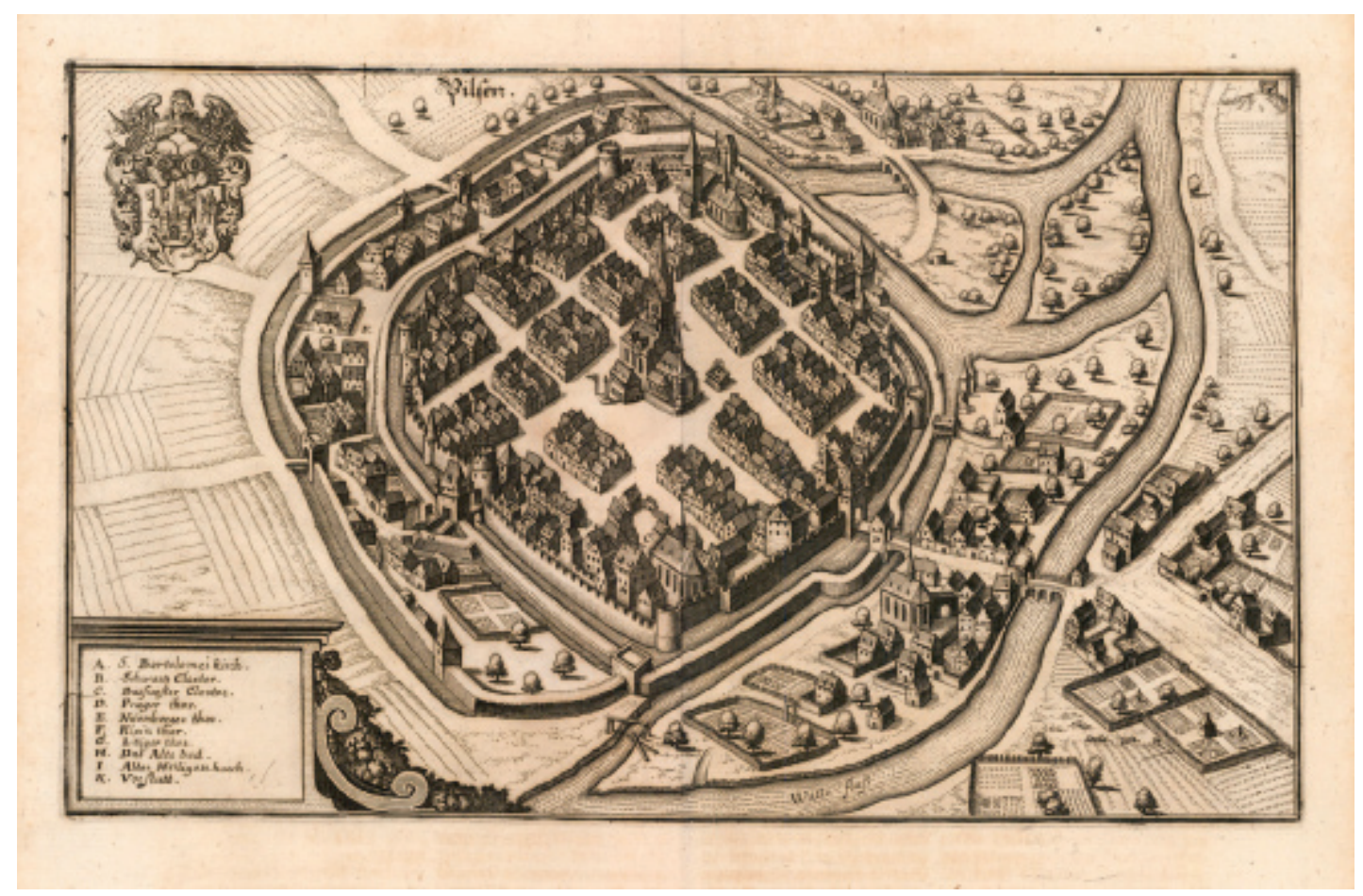

Fig. 1. La ciudad de Plzeň/Pilsen en un grabado de Matthäus Merian de 1649 (Merian, 1650: 51).

Sobre Jan Kraus nada sabemos de su infancia y juventud, excepto que estudió luego arquitectura con Ruperto Blank. Esta noticia la dieron los PP. Leonhardt y Furlong ${ }^{14}$, quienes citan una carta escrita en 1702 por Kraus a su antiguo provincial Andrés Waibel. Allí menciona a Ruperto Blank, expresando que lo "recuerda con elogio y con cariño", pues fue "quien le hizo amar el estudio de la arquitectura y le instruyó en su técnica".

Nadie se detuvo a buscar quién era este Blank. Sabemos que no fue jesuita y posiblemente trabajó en alguna de las ciudades por donde con certeza sabemos que estuvo el H. Kraus, es decir: Pilsen, Landsberg o Ingolstadt. Lo cierto es que la arquitectura era un oficio, cuya enseñanza no se oficializó hasta el Siglo XVIII con la creación de las Academias. Por el tiempo del H. Kraus, despertada la vocación, los jóvenes se acercaban a algún maestro quien le enseñaba el arte que incluso podría ser un familiar. Pero se comenzaba desde muy joven a trabajar en la albañilería y ya en la madurez recién llegaban a ser mencionados como arquitectos. Es decir que había que ganarse el título por parte de la comunidad, previo a ser considerado baumeister, dombaumeister, es decir maestro constructor, que era a lo que se podía aspirar en la Alemania (y en toda Europa) del Siglo XVII.

Recién volvemos a tener noticias del H. Kraus el 27 de octubre de $1685^{15}$ cuando ingresó a la Compañía de Jesús de la provincia de Alemania Superior ${ }^{16}$. Lo hizo en la ciudad de Landsberg

\footnotetext{
14 LeONHARDT y FurLONG, 1921: 56.

15 STORNi, 1980: 155.

16 Para Huonder ingresó el 28 de octubre de 1689.
} 
(Alta Baviera), donde posiblemente estudió; o quizás también en Ingolstadt, donde profesó sus últimos votos el 2 de febrero de 1696. Este colegio era por aquel tiempo el más importante de la provincia (fig. 2). De neta formación humanista, se destacaba por la enseñanza de las matemáticas, en las que sobresalió el P. Jakub Kresa a quien el H. Kraus quizás conoció en Cádiz, donde enseñaba.

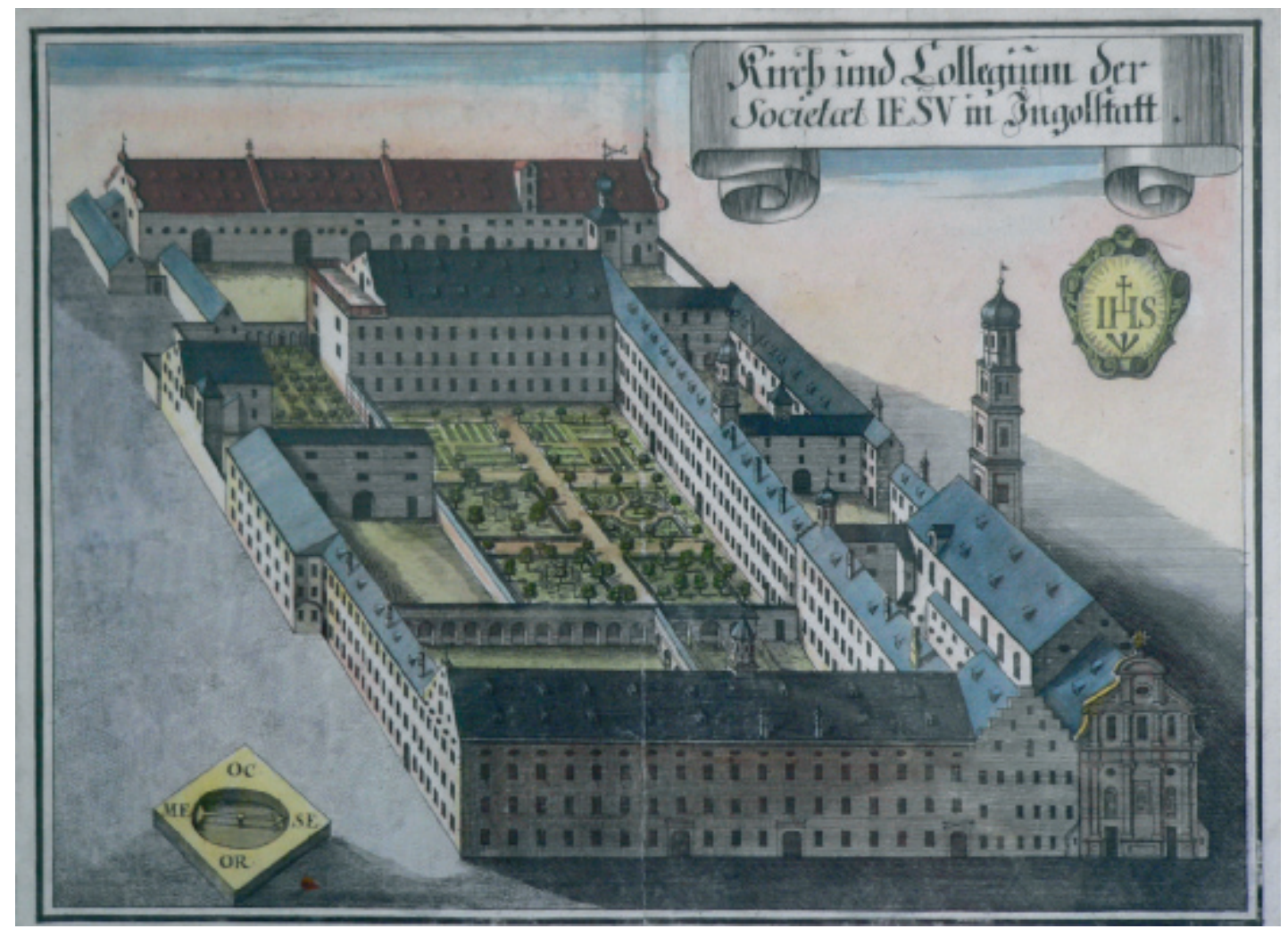

Fig. 2. Colegio jesuítico de Ingolstadt en un grabado en cobre de Michael Wening, 1701 (Schuster, 1999).

Desde una de estas ciudades, posiblemente Ingolstadt, escribió su carta indipeta, dirigida al general de la Compañía de Jesús, aunque no la hemos localizado ${ }^{17}$. ¿Qué lo motivó?. Seguramente la amplia literatura jesuita que circulaba por Europa, además de una importante literatura hagiográfica, sobre todo la que hacía referencia a las misiones guaraníticas. Pero sabemos sobre todo que precisamente en Plzeň/Pilsen el tipógrafo Mikulás Bakalár Štetina publicó sobre el Nuevo Mundo en 1506 en lengua checa, libro que no podía faltar en ninguna biblioteca jesuítica.

17 ARSI, Fondo Gesuitico, FG 754, Germania Superior (1661-1770) - Germania Superior 18 I-II-III (1612-1729)

Arch. esp. arte, LXXXVII, 347, JULIO-SEPTIEMBRE 2014, 245-262

ISSN: 0004-0428, eISSN: 1988-8511, doi: 10.3989/aearte.2014.16 
Finalmente el provincial de Bohemia P. Enrique Schmidt, autorizó el viaje del H. Kraus y el del H. Enrique Peschke, en Praga el 7 de enero de 1697. Y el 25 de marzo, ambos ya estaban en Sevilla $^{18}$. Sugestivas fechas que hacen pensar que viajaron juntos, aunque no hay prueba.

\section{El viaje a Buenos Aires}

Viajar a las Indias españolas era problemático para los extranjeros, pero también lo era pues debían salvar los peligros de cruzar el océano. Las causas eran la fragilidad de las embarcaciones, el asecho de los corsarios y también la larga espera que implicaba conseguir un navío, que partiera al Río de la Plata. Pero esa espera debe haberle beneficiado en aprender el idioma y profundizar sus conocimientos en arquitectura en Cádiz y especialmente Sevilla, donde debe haber conocido al maestro Leonardo de Figueroa, trabajando en la iglesia de los dominicos de San Pablo, en la del Salvador y en nada menos que en la de San Luis de los Franceses.

Lo reclutó el procurador a Europa por la provincia del Paraguay el asunseño P. Ignacio de Frías, electo en la XIII Congregación Provincial de 1689. Entre las gestiones del P. Frías en Europa mencionemos que logró del Papa Inocencio XII el breve Adeo nobis cordi est del 26 abril 1695, solicitando a la Corona que se permita el ingreso de misioneros súbditos de Italia y Austria $^{19}$.

La licencia del monarca al P. Frías fue concedida el 13 de diciembre de 1694. En ella se autorizó embarcar a cincuenta sacerdotes y seis coadjutores ${ }^{20}$, pudiendo llevar seis extranjeros. Pero pasaron tres años y el procurador solo pudo conseguir treinta y ocho religiosos.

El P. Frías describe a cada uno, mencionando del H. Kraus: "mediano de cuerpo, de pelo castaño, carirredondo, ojos sarcos". Pero también solicitó a las autoridades que se le acuda con "el viático, entretenimiento, malotaje y pasaje hasta Córdoba". Con lo que el contador de la Casa de Contratación decidió otorgarle a cada uno "7 reales y 8 leguas al día y más 2 reales mientras aguardan en Sevilla embarcación" 21.

El viaje de Praga a Sevilla que realizó el H. Kraus debe haber sido similar al que describe el H. Peschke, especulando que posiblemente lo hicieran juntos. Pues el boticario habla de su "largo viaje de Bohemia a América, por Génova y Cádiz”.

Como dijimos, según Borges Morán, el H. Kraus, de 32 años, había llegado de Praga a Sevilla el 25 de marzo de 1697. Su larga espera en Sevilla aconteció en el Hospicio de Nuestra Señora de Guadalupe, contiguo al Colegio de San Hermenegildo.

A fines de abril de 1698 la expedición partió del puerto de Cádiz con rumbo al Río de la Plata en varios barcos a cargo del maestre Juan de Orbea ${ }^{22}$. Tanto el H. Peschke como el P. Fanelli ${ }^{23}$ cuentan que llegados al puerto subieron a unos botes que los condujeron a los barcos. En uno iban jesuitas para Chile y en tres navíos se embarcaron los del Paraguay.

Entre los jesuitas y compañeros reclutados con el H. Kraus, se encontraban Jerónimo de Herrán, Sebastián de San Martín y Antonio Machoni que serían con el tiempo provinciales. Los dos últimos al igual que Juan de Alzoa fueron procuradores a Europa. Además solo viajó un compatriota, el mencionado coadjutor médico y boticario de Silesia, el H. Enrique Peschke (16741729).

\footnotetext{
18 Pastells, 1923: 393 y Borges Morán, 1977: 287.

19 Historia T.1, 1600-1695. ARSI, Paraq. 11, f. 514-521.

20 PASTELls, 1923: 310.

21 PASTELLS, 1923: 385.

22 Galán García, 1999: 287.

23 PAgE, 2007: 121.
} 
El H. Kraus cumplió sus años en medio de la travesía, arribando a Buenos Aires el 24 de setiembre de 1698. Mientras que el H. Peschke, relata el viaje de Buenos Aires a Córdoba, expresando que luego de descansar en el Colegio porteño y después de haber recibido la bienvenida hasta por el gobernador, emprendieron el viaje. Escribe que partieron de Buenos Aires el 1. ${ }^{\circ}$ de diciembre de 1698 y el 22 llegaron a Córdoba. "Estábamos en chozas de junco y paja, con bastante comodidad, que están construidas sobre carretas de dos ruedas tiradas por bueyes que se relevan". Al arribar a Córdoba y como era costumbre, salió a recibirlos en las afueras de la ciudad, el rector del colegio y su comitiva. Cuando ingresaron a la ciudad se escucharon las campanas de todas las iglesias y fueron conducidos a la iglesia y luego al colegio. Destaca la "hermosa capilla del Noviciado", mientras que del colegio escribe "en magnitud y arte, no cede en mucho al de San Clemente en Praga. O así en altura, pues solo tiene dos pisos" ${ }^{24}$. Insistimos que no quiere decir que Kraus y Peschke hayan viajado juntos, pero seguramente lo hicieron en similares condiciones. Pues el boticario detalla a continuación: "Eramos diez jesuitas con veinte carretas, dos para cada uno, con 400 bueyes de tiro. Hubiéramos sido 24 si el tercer barco en que venían 14 de nuestros misioneros, no hubiese quedado atrás y llegado demasiado tarde".

No sabemos cuánto tiempo permaneció el H. Kraus en Córdoba en estos primeros meses. El P. Furlong manifiesta que en 1702 estaba en el pueblo de San Juan ${ }^{25}$, que fue la última reducción por la que pasó.

En los Catálogos de la Provincia del Paraguay, el H. Kraus figura en solo tres, de los que se conservaron de sus 16 años en el Río de la Plata. En el de 1700 lo encontramos en Buenos Aires ${ }^{26}$. En el de 1703 no solo no se lo ubica en ningún lugar en particular sino que se lo hace al final como "Praetermisi" (omitido), pero señalándolo como "Domestica architectus" 27 , es decir con tareas de arquitecto, mencionándose por primera vez su trabajo. Y en el catálogo secreto del mismo año también se repite tal actividad ${ }^{28}$. El próximo y último catálogo es el de 1710 , que lo ubica en el colegio de Buenos Aires como "curam habet de fabricis", o sea "a cargo del cuidado de los edificios" 29 .

\section{El H. Kraus en las misiones orientales}

Relatan los PP. Leonhardt y Furlong ${ }^{30}$, siguiendo la carta que en 1702 escribió el H. Kraus, que después de Córdoba lo destinaron: "a Yapeyú y Santo Tomé, después a San Miguel y por fin a San Juan donde levantó el plano de una iglesia y ayudó al P. Sepp en la fundación de dicho pueblo, como anteriormente había ayudado a la fundación del de Santo Tomé".

Pero esta estadía en las reducciones fue corta. Así lo redactó el P. Sepp cuando el 4 de noviembre de 1714 le remitió al mismo superior alemán la noticia de su muerte y que envíe otro arquitecto, afirmando al respecto que fue muy útil: "durante el año que pasó en las misiones" 31 .

\footnotetext{
24 MuHN, 1946: 47-48.

25 Furlong, 1945: 127.

26 Catálogo Trienal 1669-1677. ARSI, Paraq. 4-2, f. 489v.

27 Catálogo Trienal 1703-1762. ARSI, Paraq 6, f. 20.

28 Catálogo Trienal 1703-1762. ARSI, Paraq 6, f. 34.

29 Catálogo Trienal 1703-1762. ARSI, Paraq 6, ff. 40 y 49.

30 LEONHARdT Y FurLONG, 1921: 52.

31 WERNICKE, 1940: 360-364. SEPP, 1974: 137.
}

Arch. esp. arte, LXXXVII, 347, JULIO-SEPTIEMBRE 2014, 245-262

ISSN: 0004-0428, eISSN: 1988-8511, doi: 10.3989/aearte.2014.16 
Por su parte el procurador Francisco Burgés, en correspondencia dirigida al general Tamburini, manifestó que Kraus: "es el único artífice en toda la provincia"32, amén que había uno que otro carpintero, cuyo oficio en aquella época y en más de una oportunidad lo habilitaba en la práctica edilicia.

Los cuatro pueblos que menciona el H. Kraus eran de distintas épocas y por tanto de diferentes desarrollos urbanos y arquitectónicos. Nuestra Señora de los Reyes del Yapeyú se ubicó a orillas del río Uruguay, y de su iniciación nos da cuenta el provincial Nicolás Mastrilli Durán en su Carta Anua (1626-1627) expresando que lo fundaron los PP. Roque González de Santa Cruz y Pedro Romero en el verano de 1627, con sementeras, iglesia y casa para los sacerdotes ${ }^{33}$. En cuanto a Santo Tomé, se la ubicó en 1632 en la margen derecha del río Yaguary, a cargo del belga Luis Ernot y el francés Noël Berthot. Pero las incursiones de los bandeirantes, enfermedades y demás calamidades forzaron a trasladar la población. De la iglesia de Santo Tomé escribe el P. Oliver "es una de las mejores, tiene 5 altares, el mayor con un magnifico y hermoso retablo medio ochavado, y bellamente dorado con 6 estatuas" 34 . Pero a la que se refiere es a la proyectada por el arquitecto Ángel Petragrassa, de tal modo que aquella que pudo hacer o intervenir el H. Kraus fue provisoria al igual que la de San Miguel que se comenzó en 1708 interviniendo luego los arquitectos jesuitas Prímoli, Ribera y Grimau.

San Juan Bautista fue su último destino entre guaraníes. Señala Furlong que la iglesia y la casa fueron obra suya en base a la mencionada carta de Kraus. El pueblo fue fundado en 1698 por el P. Sepp con indios de la reducción de San Miguel. El P. Sepp escribe excepcionales detalles sobre sus construcciones:

"Mi primera atención fue escoger terreno para la fábrica de la iglesia y la casa del misionero: Desde allí tiré algunas líneas paralelas, que habían de ser otras tantas calles, en las cuales se habia que edificar casa para cada familia, de manera que la iglesia fuese como el centro de todo el pueblo, o el término de todas las calles".

Sigue relatando con minuciosidad cómo continuaron las obras, expresando:

"De paja era el techo, de paja las paredes, de paja también la puerta. Mi tugurio servía de refectorio, dormitorio, y hasta gallinero, pues tenía cuatro inquilinos gallináceos... Junto a esta choza levanté otra para mi compañero, a quien esperaba. Entre estos ranchos edifiqué la capilla, igualmente de paja entretejida con cañas tacuaras. Traje de San Miguel el llamado altar portátil, con cálices y demás elementos".

Agregando que en el interior: "Adorné las paredes de la capilla con algunas imágenes, y en el medio levanté un cuadro con la figura del precursor de Cristo, San Juan Bautista" 35 . Incluso describe cómo construyó una nueva iglesia, enriquecida con una estructura de madera, alcanzando tres naves con un dorado artesonado de cedro.

"En lo que toca a las columnas, cuidé que primero fuesen enterradas en una profundidad de ocho pies y bien calzadas con piedras, de suerte que después podian ser levantadas sin temor a la altura de cincuenta pies. Desde el presbiterio hasta la puerta de ingreso, inclusive, levanté venticuatro columnas en serie igual de ambos lados. Entre una y otra había una distancia de

32 Historia 1667-1785, ARSI, Paraq. 12, f. 122v. (Este documento lo citan por primera vez LEONHARDT Y FURLONG, 1921: 40).

33 LeONHARDT, 1927: 368-369.

34 Varia de historia, ARSI, Paraq. 14, f 90.

35 FURLONG, 1962: 45. 
veinte pies geométricos. Tiene tres naves, como llaman los españoles, o pórticos, el mayor en el medio, de 25 pies; los de los lados, 20”.

Entre otras cosas también menciona que tenía cinco puertas y un tabernáculo siguiendo el modelo realizado por el Hermano Leiberer en Landsberg, y una capilla octogonal según el modelo de Oettingen ${ }^{36}$. El P. Sepp, como vemos, explica cada detalle de cómo la fue levantando y al H. Kraus no lo menciona nunca, ni siquiera en algún pasaje de la citada noticia necrológica. Explica sí, que el pueblo contaba con cuatro constructores, ocho picapedreros, dos ladrilleros, ochenta obreros para la fábrica de ladrillos y cincuenta carpinteros. Pues había un modelo de iglesia que los indios levantaban con sobrada pericia y celeridad.

Estas dos iglesias que hace construir el P. Sepp, parece que quedaron prácticamente inútiles, pues en dos documentos que trae Levinton, señala que en una visita que hizo el P. Diego Garvia en 1713, menciona que los cimientos de la iglesia resultaron defectuosos, por lo que un año después el provincial Luis de la Roca ordenó que se vuelva a edificar el templo semejante al de San Nicolás y que será el definitivo. Iglesia que por otro lado también fue modelo para la del pueblo de San Luis Gonzaga y otras, pues el mismo Superior había establecido como norma que ninguna iglesia que se construyera superara las dimensiones de la de San Nicolás o San Ignacio Guazú $^{37}$. Incluso se levantaron cimborrios, más bajos que la de San Borja, contemporánea a la de San Nicolás, que junto con las de Santa Ana e Itapúa construía por entonces el coadjutor italiano Brasanelli ${ }^{38}$.

Seguro es que el H. Kraus estuvo en algún momento y posiblemente ayudó en la construcción, aunque Sierra es quien le atribuye categóricamente el proyecto y Levinton lo ratifica ${ }^{39}$. El P. Oliver describe esta iglesia para la época de la expulsión: "Grande con sus tres naves, media naranja, y muy clara, acabada ya con toda perfección" 40 .

Un completo relato del estado de los pueblos en 1714 nos dejó el P. Sepp, al señalar el florecimiento de las por entonces 31 reducciones. Cuenta que los guaraníes eran tan diestros para los trabajos que reúnen todos los oficios y artes:

“el que mañana funde campanas, será, el próximo día de fiesta, director de orquesta”. Sobre las iglesias escribe generalizando: "Son de construcciones abovedadas, divididas en tres o cinco naves laterales o columnatas, doscientos pies de largo y ochenta de ancho, adornadas con una cúpula a la manera italiana, cerca del coro. Cada iglesia tiene tres o cinco hermosos altares, tallados en madera olorosa de cedro" $"$.

Sobre San Juan Bautista existe el conocido plano que el provincial José Barreda le envió junto a su informe sobre el Tratado de Límites al P. Ravago, el 31 de julio de 1753, donde enfatiza que las reducciones no eran aldeas portátiles sino que tenían edificios hechos de piedra y tejas $^{42}$ (fig. 3).

Levinton $^{43}$ le adjudica al H. Kraus la autoría de la iglesia de Salta, sin documentar su presencia. Sin embargo su lenguaje bávaro se debe efectivamente a la intervención del H. José Schmidt

36 FurlONG, 1966: 60.

37 LeVINTON, 1998: 18 a 21.

38 SUSTERSIC, 1999: 58-59

39 LeVinton, 1998: 20.

40 Varia de Historia. ARSI, Paraq. 14, f. 92.

41 SEPP, 1974: 179, 180 y 193.

42 Plano de la reducción de San Juan Bautista c. 1753. Archivo General de Simancas (AGS), Secretaría de Estado, Legajos, 07381, 71. Copia en Biblioteca Nacional de Francia, GeC2769.

43 LeVINTON, 1998: 25.

Arch. esp. arte, LXXXVII, 347, JULIO-SEPTIEMBRE 2014, 245-262

ISSN: 0004-0428, eISSN: 1988-8511, doi: 10.3989/aearte.2014.16 


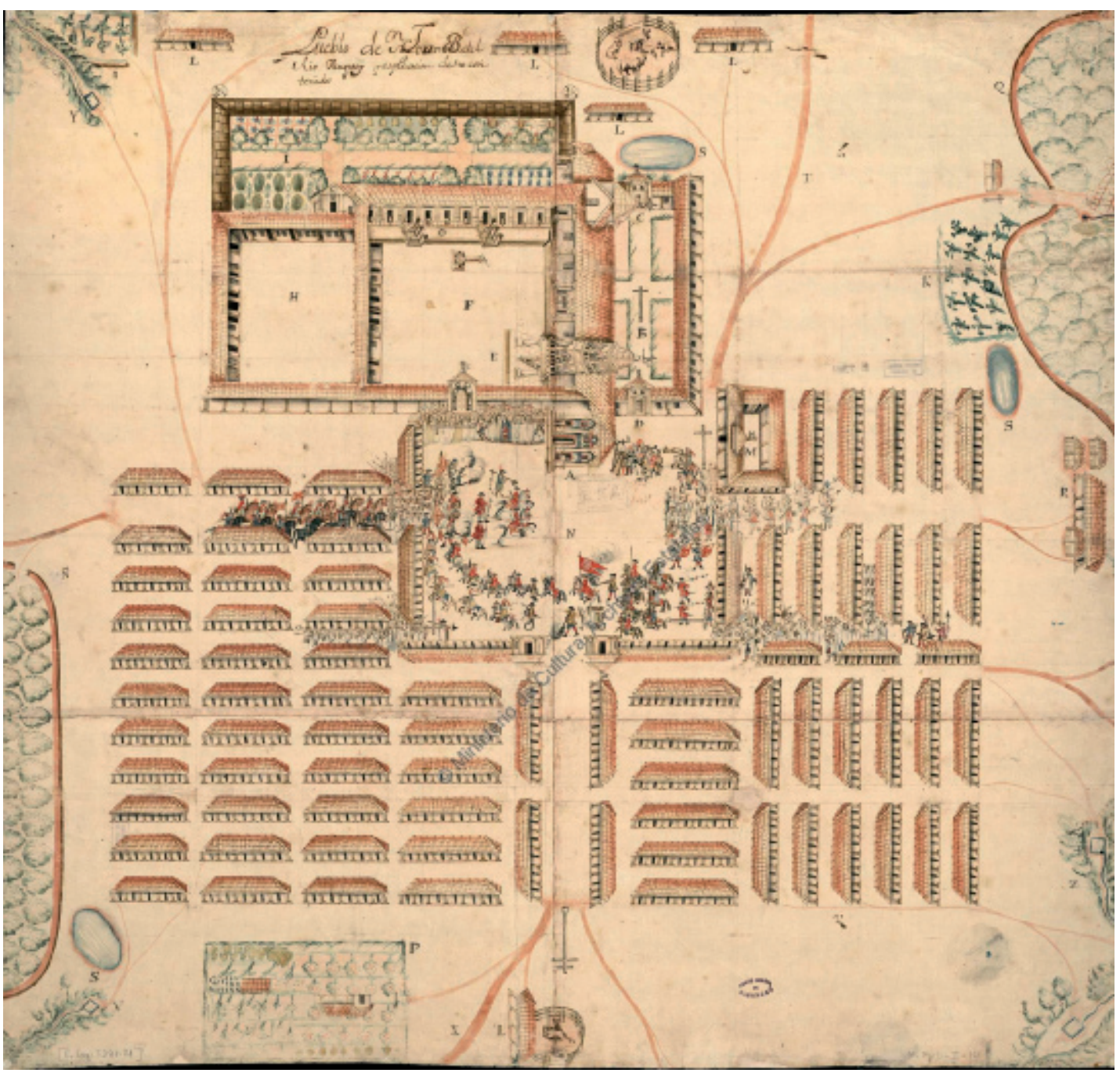

Fig. 3. Plano de San Juan Bautista c. 1753 (Archivo General de Simancas, MPD 02 014).

que fue enviado a Salta entre 1720 y 1724, luego de la muerte de su iniciador el coadjutor madrileño Juan Vizcaíno. Pero la iglesia seguramente la concluyó el bávaro Johann Wolff en $1757^{44}$.

\section{El colegio y la iglesia de San Ignacio en Buenos Aires}

El 31 de enero de 1696 durante el provincialato del P. Lauro Núñez, el general Tirso González hizo un breve recuento de las obras realizadas hasta el momento, expresando que ya se había

44 Page, 2013a: 82-83. 
acabado la iglesia del colegio de Asunción, se iniciaba la de Santa Fe y la residencia de Tucumán. Mientras que el templo de Buenos Aires amenazaba ruina.

Pero para tratar la obra de la iglesia porteña en particular nos remitiremos al P. Furlong 45 quien se refiere extensamente a ella y al colegio, como lo hicieron otros historiadores ${ }^{46}$. Escribe que en 1661 los jesuitas dejaron el solar de la plaza mayor y se mudaron a su último sitio, hasta que en 1675 se inauguró el nuevo templo. Pero igualmente se fue mejorando su aspecto, incluso pretendiendo construir una nueva iglesia, para la que se estaban quemando ladrillos y tejas desde 1686, elevando una torre y la fachada en 1691. Extrañamente las naves de la iglesia se levantaron luego, a partir de 1710. El visitador Antonio Garriga manifestó que para levantar la nueva debían conservar la única torre, portería y la fachada. De esta manera había que comenzar con los cimientos y para ello se aprobó el plano de cinco capillas propuesta por el $\mathrm{H}$. Kraus, en desmedro de otro de cuatro, posiblemente del mismo coadjutor ${ }^{47}$. En este aspecto su similitud con la planta de la iglesia del Colegio Imperial de Madrid la han señalado muchos autores, aunque esta posee capillas de diferentes dimensiones, pero comparte un nártex flanqueado por las escaleras de ingreso a las torres. Igualmente existen ejemplos germánicos, pero posteriores.

Además de ello, el provincial le ordenó al $\mathrm{H}$. Kraus que se hiciera cargo de fabricar hornos de cal y conseguir piedras para los cimientos. Todo, con la mayor premura posible, y que al menos se techara cuanto antes hasta las tres primeras capillas. Es posible que el mismo constructor checo le retocara la fachada, como manifiestan varios autores, y hasta le elevara las torres, aunque la obra la continuó dirigiendo el H. Johann Wolff, que era bávaro (figs. 4 y 5).

La fachada contiene ciertamente torres de cinco niveles al modo centroeuropeo, que la alejan del modelo madrileño de su planta. Señala Stěpánek ${ }^{48}$, que la composición de cornisas ricamente modeladas del portal semejan por su ejecución a la iglesia de la "Virgen de las Mercedes de Salzburgo", obra del arquitecto austríaco Johann B. Fischer von Erlach (Graz, 1656-Viena, 1723). Pero es indudablemente que esa iglesia no las conoció el H. Kraus. Es más probable que los detalles decorativos, como las altas ménsulas invertidas y guirnaldas fueran realizadas al finalizar el templo por el bávaro Pedro Weger.

Con la muerte del $\mathrm{H}$. Kraus se suspendieron las obras que parece habían alcanzado el objetivo de las tres capillas como lo comprobó el arquitecto Buschiazzo, pues las tres primeras tienen bóvedas de arista y el resto de casquetes esféricos. La iglesia quedó concluida y consagrada en 1734, habiendo intervenido luego los arquitectos italianos Bianchi y Prímoli. Incluso y en la parte final, el mencionado coadjutor Weger, falleció al caerse de un andamio de la iglesia en $1733^{49}$. Por tanto no se sabe con exactitud en qué intervinieron los italianos y germanos, resultando una obra barroca con fuerte acento italiano a la que se asocia lo germánico solo como lenguaje periférico de aquel.

\section{Los ambiciosos proyectos del provincial Lauro Núñez en Córdoba}

Cuando el H. Kraus llegó a Buenos Aires, fue nombrado provincial el P. Ignacio de Frías y rector del Colegio Máximo el P. Lauro Núñez quien ya había sido provincial (1692-1695). Lue-

45 Furlong, 1944: 147-182

46 Buschiazzo, 1939.

47 Este plano fue publicado por primera vez por el P. Furlong quien los halló en el Colegio de la Inmaculada en Santa Fe junto con otros (Furlong y Buschiazzo, 1942: 450-471). Pero esta invalorable colección hoy se encuentra desaparecida, excepto la planta del colegio de Córdoba.

48 STĚPÁNEK, 1982: 246.

49 De Paula, Gutiérrez y Viñuales (s/f): 20.

Arch. esp. arte, LXXXVII, 347, JULIO-SEPTIEMBRE 2014, 245-262

ISSN: 0004-0428, eISSN: 1988-8511, doi: 10.3989/aearte.2014.16 


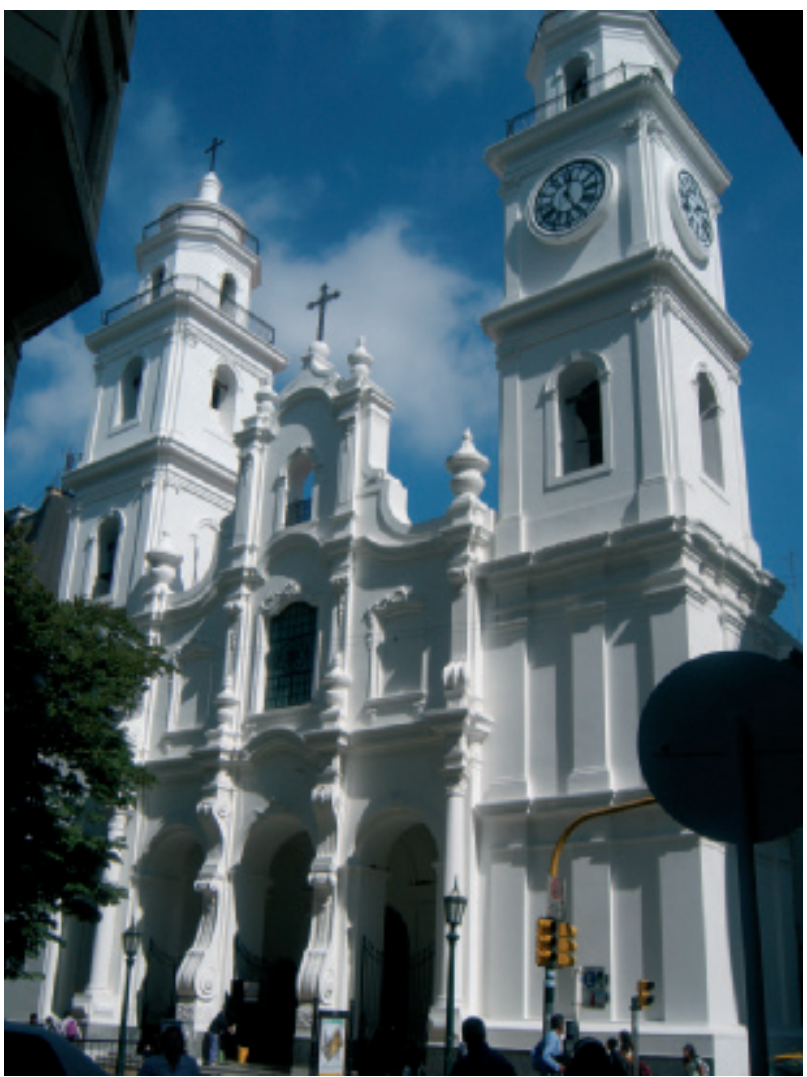

Fig. 4. Fachada de la iglesia de la Compañía de Jesús en Buenos Aires.

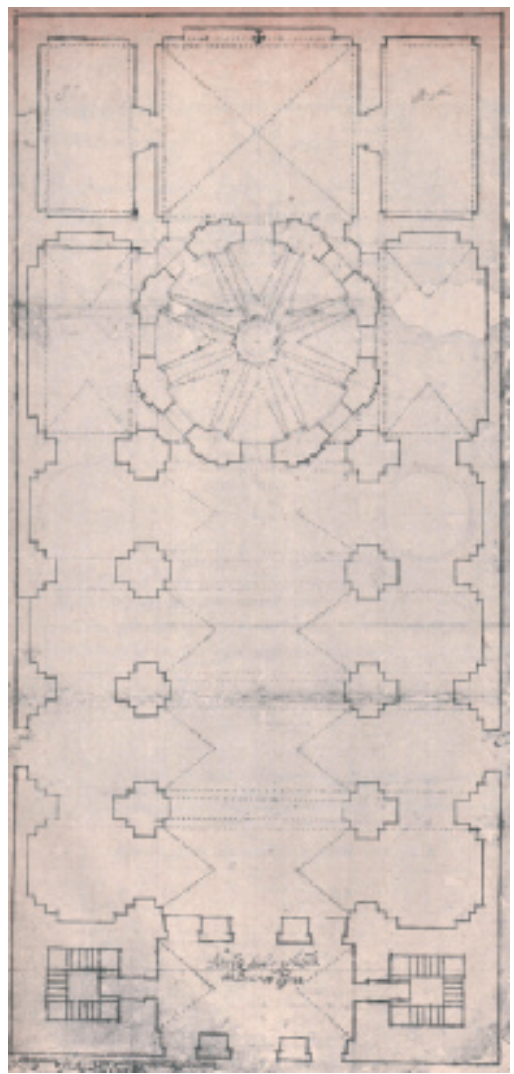

Fig. 5. Planta de la iglesia de San Ignacio publicada por Furlong y Buschiazzo (1942).

go de ese cargo fue Maestro de Novicios, con lo que conocía muy bien la situación edilicia de ambas instituciones, tanto del Colegio como del Noviciado, cuando fue nombrado provincial por segunda vez en 1702. Incluso gracias a las gestiones de su primer mandato se pudo concretar la donación de una casa con destino al Convictorio. Pues en estos tres edificios intervino probadamente el H. Kraus ${ }^{50}$.

El P. Lauro fue apoyado por el general Tirso González y varios compañeros, como los PP. Simón de León, Blas da Silva, Ignacio de Frías y Gregorio Cabral con quienes alternó el provicialato y el rectorado de la universidad. Todos ellos, especialmente el P. Núñez, impulsaron notablemente las obras edilicias que necesitaba Córdoba, como a su vez la inconclusa iglesia del Colegio ocupándose de la decoración interior ${ }^{51}$. Pero el uso de fondos para estas obras, en desmedro del dinero que debía sostener a los procuradores en Europa y sus visitas a la provincia, le creó enemigos internos como el P. Francisco Burgés, y el mismo general Tamburini que envió al P. Antonio Garriga como visitador-provincial para suspender todas estas obras.

\footnotetext{
50 Page, 1999: 37-45 y Page, 2011c: 199-232.
}

51 PAGE, 2011b: 625-648. 
El Noviciado de la Provincia del Paraguay ${ }^{52}$ fue creado por el P. Diego de Torres en 1607 dentro de la manzana donde se levantaría el Colegio Máximo, aunque siempre los superiores incentivaron que no estuvieran próximos, como el general Nickel y su sucesor González. La solución afloró pocos años después con la donación de una casa, destinada al Noviciado, que realizó en 1700 el sacerdote Francisco Mujica, quien se incorporó al Instituto, acompañando a su hermano Ignacio ${ }^{53}$.

La casa de los Mujica estaba compuesta de: "una sala de cinco tirantes y una chimenea en ella, dos alacenas a los lados, dos aposentos seguidos hacia el Norte con puertas buenas, un traspatio hacia la huerta, un patio y en él otra sala y una tienda con puerta a la calle, un aposento con puerta al Sur y otro pequeño, que por todo son siete viviendas". Se aclara en el mismo documento que estaba ubicada en una manzana completa, valía 2.600 pesos y limitaba al norte con el río ${ }^{54}$ que llamaban Chiquito, que era un desprendimiento del Suquía hoy inexistente, por lo que eran tierras bajas.

Una vez efectuada la donación, el provincial P. Frías debió comenzar las obras que siguió el P. Lauro, que incluían la demolición de la casa y la incorporación al proyecto de una botica y obviamente una capilla, de la que se conservó su cripta (fig. 6). De tal manera es oportuno completar el mencionado texto del P. Burgés al general Tamburini: "más el P. Lauro quiere magnificos edificios, y para ese fin ha traído al Hermano Kraus al Noviciado de Córdoba, el único

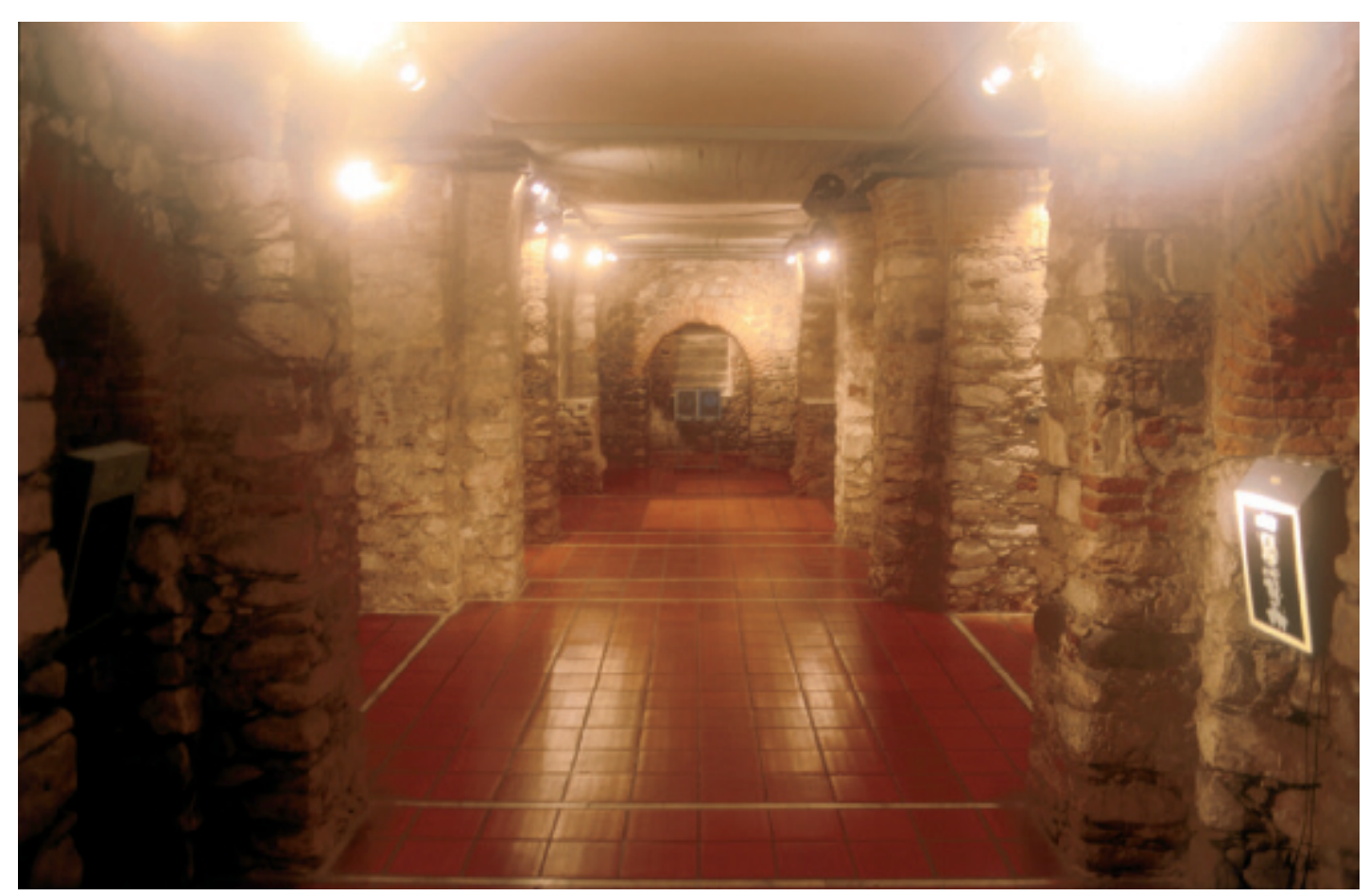

Fig. 6. La cripta de la inconclusa capilla del antiguo Noviciado de los jesuitas en la actualidad.

\footnotetext{
52 Page, 1999 y Page, 2013a.

53 Storni, 1980: 194-195. LuQue Colombres, 1980: 175. Page, 2004: 282-283.

54 LuQue Colombres, 1980: 238.
} 
artifice que hay en toda la provincia, privando de él al Colegio de Buenos Aires, que necesita de casa, por caerse lo que tiene" 55 .

Las obras del Noviciado se suspendieron en 1713 por orden del general quien, después de recibir las acusaciones del P. Burgés, mandó construir una nueva casa separada, de dos plantas, dentro de la manzana del colegio, también proyectada por el H. Kraus. En esta decisión seguramente fue importante la opinión del mencionado P. Garriga, a quien el P. Tamburini le manifestó, en forma reiterada y finalmente el 4 de abril de 1713: "Teniendo ordenado ya, que los novicios se críen, no en la casa del noviciado, sino en el Colegio de Córdoba", porque: "estando la Casa del Noviciado tan pobre, no hay necesidad de hacer una iglesia tan magnifica, que sería inútil, aunque estuviese muy rica. Ordeno que se suspenda la fábrica de dicha iglesia" 56.

El P. Orosz ${ }^{57}$ al biografiar al P. Lauro, menciona del nuevo edificio del Noviciado: "Núñez, con la aprobación de quienes convivía, construyó hasta el final una amplia casa a la que trasladó a los novicios. Al mismo tiempo, también puso los cimientos del templo, pero como por mandato severo de los superiores se le prohibió continuar, se les mandó a los nuevos moradores volver a la antigua residencia".

La casa de los Mujica convertida en Noviciado quedó abandonada y en 1725 fue habilitado el nuevo Noviciado ${ }^{58}$. El destino del Noviciado "aparte" (antes casa de los Mujica) fue mencionado en la Consulta del provincial de 1736, quien preguntó si: "era conveniente conservar la casa del Noviciado de abajo para dar Ejercicios a los hombres" "59.

En los inventarios de la expulsión se trata de su "iglesia subterránea de tres naves por concluir". Todo desapareció con el tiempo y la implacable piqueta demoledora, hasta que en 1990 se escavaron y recuperaron las ruinas de la iglesia ubicada bajo una avenida que había sido abierta en 1928.

La creación del Convictorio (fig. 7) también se le debe a la iniciativa del P. Núñez. La vivienda del donante Ignacio Duarte y Quirós, que había sido heredada de su padre, se componía hacia 1687 de "siete piezas de edificio, zaguán, patio, traspatio y un pozo de sacar agua". Pero los jesuitas recibieron en donación y compra el resto de la manzana. Si bien los colegiales la ocuparon en solemne ceremonia en 1695, el P. Lauro quiso adecuar la casa y encargó el proyecto al H. Kraus, aunque sin poder avanzar en el mismo, por las diferencias con el general Tamburini. Esto se desprende de documentación posterior, cuando el 30 de junio de 1732 se decidió continuar con la obra y el provincial preguntó a sus consultores "si se había de proseguir según la planta antigua hecha por el H. Kraus y aprobada por los PP. Provinciales, o según otra que había ideado el H. Bianchi, y a que se inclinaba el P. rector del Convictorio, por algunos reparos $e$ inconvenientes de la antigua". El reclamo del rector P. Luis de los Santos no convenció a los consultores, quienes fueron a inspeccionar el edificio y finalmente, el 2 de marzo de 1734, determinaron: "y todos fueron de parecer, que la Capilla se hiciera según la planta antigua, apro-

55 Historia 1667-1785. ARSI, Paraq. 12, f. 122v.-123.

${ }^{56}$ Carta del P. Miguel Ángel Tamburini al vice provincial, Roma, 4 de abril de 1713 (2. carta). En: PAGE, 2013b: 276.

57 TeCHO, 1759.

58 Según los inventarios realizados pata la expulsión, el Noviciado contaba con aposentos en la planta baja y siete en la planta alta con una despensa pequeña. En el claustro bajo había un nicho con una imagen de Nuestra Señora del Pilar, mientras que en la escalera que unía ambas plantas había dos nichos, una con la imagen de Jesucristo y otra con la de Nuestra Señora de los Dolores que aún se conservan. Se destaca de todo este conjunto, la ricamente ornada Capilla Doméstica y su sacristía. Luego de la expulsión, el edificio del Noviciado fue utilizado para tribunal y cárcel, mientras que en una habitación abierta hacia la calle Caseros, seccionada a la Capilla Doméstica, funcionó la Administración de Tabacos. Recién en 1792 el marqués de Sobremonte le dio el destino de Casa de Ejercicios (PAGE, 1999: 85 a 88).

59 Libro Consultas, 1731-1747, AGN-BN, leg. 69-70, f. 51v.

Arch. esp. arte, LXXXVII, 347, JULIO-SEPTIEMBRE 2014, 245-262 ISSN: 0004-0428, eISSN: 1988-8511, doi: 10.3989/aearte.2014.16 


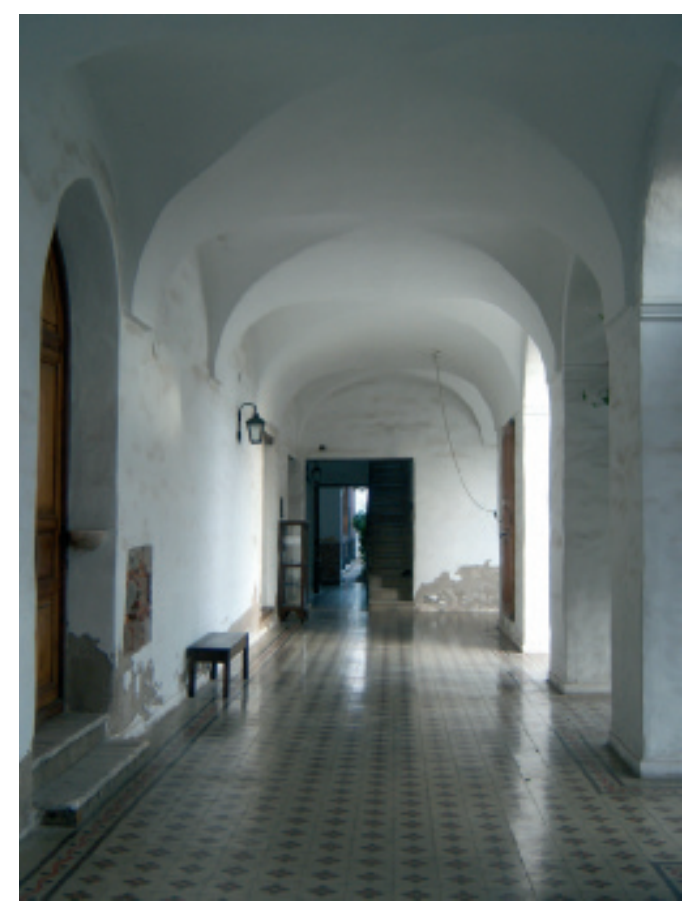

Fig. 7. Claustro del antiguo Convictorio jesuítico. Pisos calcáreos del Siglo XX.

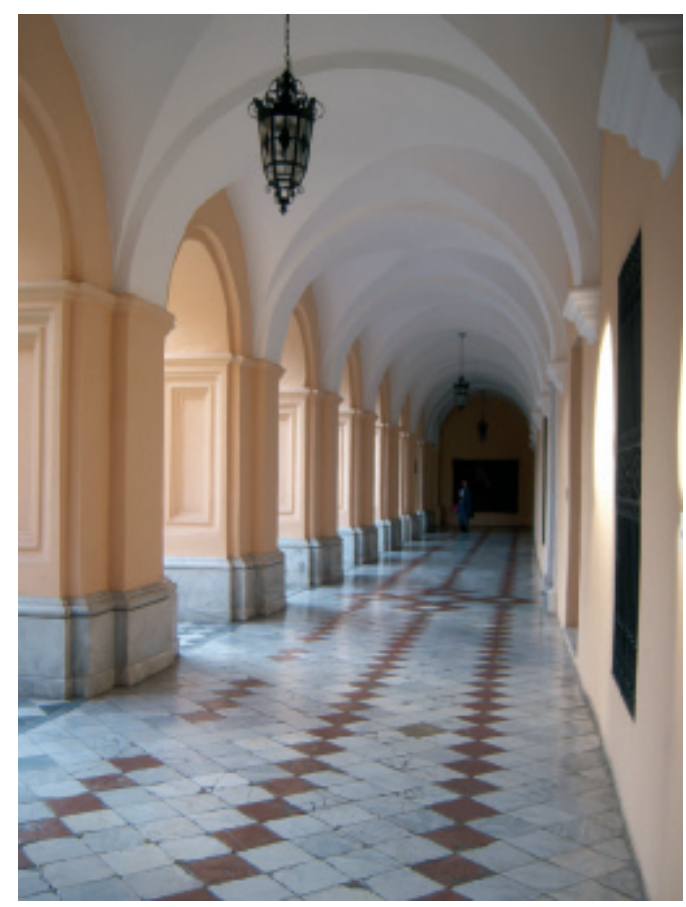

Fig. 8. Claustro de la Universidad cuyas bóvedas realizó el H. Kraus. Pisos y zócalos de mármol corresponden al Siglo XIX.

bada por tantos provinciales, rectores" ${ }^{\prime 60}$. Así lo determinó el provincial Jaime de Aguilar ordenando que se emprendiera la capilla "según y como estaba dispuesta en la planta antigua"61. Finalmente fue bendecida el 24 de noviembre de $1737^{62}$. También este edifico fue expoliado a los jesuitas y el obispo de turno fundó allí un colegio de niñas huérfanas.

Incluso tenemos cifras de lo gastado en ambas obras. Efectivamente en 1713 el P. Tamburini se enteró del monto, lo cual le causó exasperación, que se emplearan 81.580 pesos, distribuidos en 60.980 para la iglesia del Noviciado y 20.600 en la fábrica del Convictorio ${ }^{63}$. Por tanto ordenó inmediatamente "que se suspenda la fábrica de dicha iglesia" 64 . Otra obra que aparentemente realizó el H. Kraus por entonces, la encontramos en un memorial que dejó el provincial Blas de Silva (1706-1709) sin fechar. Según los términos del mismo, el H. Kraus estaba por llegar a Córdoba y ordenaba que se fueran previniendo ladrillos y cal para las obras del colegio. Estas son claramente definidas: "que se teche la sacristía y cubra con teja" y que una vez finalizada esta obra se construyan "lugares (baños) nuevos por falta de ellos". Agrega que los corredores del patio principal serán de "bóveda de ladrillo y para eso es necesario que el H. Juan Kraus, cuando venga a trabajar en ella venga a hacerla porque los albañiles del Colegio no saben” (fig. 8). Se

\footnotetext{
${ }^{60}$ Libro Consultas, 1731-1747, AGN-BN, leg. 69-70, f. 21.

${ }^{61}$ Memorial del P. Aguilar al Convictorio. Córdoba, 20 de abril de 1734. AGN, Sala IX, 6-9-6.

62 Cartas Anuas 1735-1743, BCS, Estante 12.

${ }_{63}$ Carta de Miguel A. Tamburini al P. Vice Provincial (3. a carta), Roma, 4 de abril de 1713. En: Page, 2013: 277.

${ }^{64}$ Carta de Miguel A. Tamburini al P. Vice Provincial (2. ${ }^{a}$ carta), Roma, 4 de abril de 1713. En: PAGE, 2013: 276.
} 
refiere también a la inminente obra del tajamar de la estancia de Alta Gracia que, si bien no lo menciona, seguramente el $\mathrm{H}$. Kraus fue a supervisarla ${ }^{65}$.

\section{Conociendo al H. Jan en los testimonios de su época}

Más allá del oficio que desempeñó y de sus obras, que nos llegaron o no, Kraus fue un hombre con virtudes que sobrepasan las acciones profesionales. Y que indudablemente perduran, pues aunque casi no lo hagan sus edificios de piedra, ladrillo y cal, conservamos la memoria de quienes lo conocieron y recordaron con verdadera admiración ante una personalidad tan cercana a los misioneros jesuitas de los Siglos XVII y XVIII.

En la carta del P. Sepp, que publica primero Wernicke y luego Hoffmann, mencionando el fallecimiento del H. Kraus, expresa:

"El muy amado hermano Juan -para que yo lo diga en pocas palabras- fue un egregio despreciador de sus haberes y de sus emolumentos; él no usaba ropaje sino raído; poco concedió al sueño; extendió los trabajos manuales hasta tarde en la noche soportando de continuo la molestia del día y del calor. Atento a los deberes de Marta no omitió de unirlos con las contemplaciones de Magdalena; en raras veces (fué) inducido al vino y eso sólo por orden de los Superiores; de ahí el hecho real de que paulatinamente despojado de fuerzas él sucumbiere bajo la carga. Él fue muy amigo de la pobreza; un singular ejemplo de la obediencia y de la castidad; un insigne espejo de humildad, devoción y afabilidad; una víctima de la caridad y un no vulgar adorno de los hermanos colaboradores; un acérrimo enemigo del ocio, muy paciente en las labores; en una palabra: hecho desde nacido un constante en todo, pronto para todo, apto para todo"66.

En cuanto a las Cartas Anuas que se escribieron dentro del periodo que reside en el Río de la Plata solo se encuentran dos, la de 1689-1700 y la de 1714-1720. En esta última que la llevó en mano al general, el procurador Jerónimo Herrán, se menciona en tono más formal su desaparición física:

"el Hermano coadjutor temporal formado Juan Kraus, alemán de nación, el cual murió a los 61 años de edad, habiendo vivido 37 en la Compañía. Era un varón por muchos respectos muy benemérito de la Provincia, habiendo dedicado gran parte de su actividad a la construcción de este nuestro templo y del colegio de Córdoba. Era muy amante de la pobreza religiosa, incansable en el trabajo, de exacta obediencia, y amable para con todos. Quebrantado de fuerzas guardó hasta el último momento el completo uso de sus facultades mentales. Recibidos todos los sacramentos se juntó, como esperamos, con los bienaventurados del cielo, en el año $1714^{\text {"'67. }}$

Qué otras palabras pueden quedar después de estos dos elocuentes testimonios que indudablemente son más emblemáticos que su propia obra edilicia, tanto de aquella que dudamos, de la que afirmamos, y que en definitiva son, al decir de los jesuitas de entonces, meros temas temporales.

${ }^{65}$ Memorial del P. Provincial Blas de Silva para el P. rector del Colegio Máximo de Córdoba y sus Consultores, s/f. AGN, Sala IX, 7-1-2.

66 Wernicke, 1940: 360-364. SEPP, 1974: 137-138.

67 Cartas Anuas 1714-1720, BCS, Estante 12, f. 350. 


\section{BIBLIOGRAFÍA}

Borges Morán, Pedro, El envío de misioneros a América durante la época española. Salamanca: Universidad Pontificia, 1977.

Buschiazzo, Mario J., "Construcción del Colegio e Iglesia de S. Ignacio", en Estudios, Tomo 59. Buenos Aires, 1939.

Buschiazzo, Mario J., "La construcción del colegio e iglesia de San Ignacio en Buenos Aires", en Anales del Instituto de Arte Americano e Investigaciones Estéticas, N. ${ }^{\circ}$ 13, Universidad de Buenos Aires, 1960.

De Paula SJ, Alberto, Manzana de las Luces. Colegio de San Ignacio. Buenos Aires: Instituto de Investigaciones Históricas de la Manzana de las Luces, 1997.

De Paula SJ, Alberto; Gutiérrez, Ramón; Viñuales, Graciela (s/f), Influencia alemana en la arquitectura argentina, Resistencia: Departamento de Historia de la Arquitectura de la Universidad Nacional del Nordeste, 1981.

Furlong SJ, Guillermo, Antonio Sepp y su "Gobierno Temporal” (1732). Buenos Aires: Editorial Theoría, 1962.

Furlong SJ, Guillermo, Historia del Colegio del Salvador y de sus irradiaciones culturales y espirituales en la ciudad de Buenos Aires, 1617-1943. Tomo 1 (1617-1841), Buenos Aires: Colegio del Salvador, 1944.

Furlong SJ, Guillermo, Arquitectos Argentinos durante la dominación hispánica. Buenos Aires: Ed. Huarpes, 1945.

Furlong SJ, Guillermo, Misiones y sus pueblos de guaraníes. Posadas: Lumicop y Cía, 1978.

Furlong SJ, Guillermo, Buschiazzo, Mario J., “Arquitectura religiosa colonial”, en Archivum, Tomo 1, Cuaderno 2, Buenos Aires, 1942.

Galán García, Agustín, El "Oficio de Indias” de Sevilla y la organización económica y misional de la Compañia de Jesús (1566-1767). Sevilla: Fundación Fondo de Cultura, 1999.

Giura, Juan, Apuntes de arquitectura colonial argentina. Montevideo, 1941.

Gretenkord, Barbara, Künstler der Kolonialzeit in Lateinamerika. Berlin: Ein Lexikon, 1993.

Grulich, Rudolf, Der Beitrag der böhmischen Länder zur Weltmission des 17. und 18, Jahrhunderts. Institut für Kirchengeschichte von Böhmen, Mähren, Schlesien, Königstein, 1981.

Huonder, Anton, Deutsche Jesuitenmissionäre des 17. und 18. Jahrhunderts. Ein Beitrag zur Missionsgeschichte und zur deutschen Biographie. Freiburg im Breisgan, 1899.

Kalista, Zdenêk, "Los misioneros de los Países Checos que en los siglos XVII y XVIII actuaban en América Latina”, en Ibero-Americana Pragensia. Año II, Praga: Universidad Carolina, 1968.

Leonhardt SJ, Carlos, Furlong SI, Guillermo, "Tres pioneros de la civilización nacional”, en Estudios, Tomo XX, enero. Buenos Ares, 1921.

Leonhardt SJ, Carlos, Documentos para la Historia Argentina, Tomo XX, Iglesia, Cartas Anuas de la Provincia del Paraguay, Chile y Tucumán de la Compañia de Jesús (1615-1637). Buenos Aires: Facultad de Filosofía y Letras, 1927.

Levinton, Norberto, La arquitectura del pueblo de San Juan Bautista: tipología y regionalismo. Buenos Aires: Faro editorial, 1998.

Levinton, Norberto, Arquitectura de la Compañía de Jesús en Buenos Aires. La creación y el paso inclemente del tiempo. Buenos Aires: Contratiempo ediciones, 2012.

Luque Colombres, Carlos A., Orígenes de la propiedad urbana de Córdoba (Siglos XVI y XVIII). Córdoba: Universidad Nacional de Córdoba, 1980.

Merian, Matthäus, Topographia Germaniae. Bohemeiae Topographia, Moraviae et Silesiae. Franckfurt: Matthäus Merian, 1650.

Muhn SJ, Juan, La argentina vista por viajeros del siglo XVIII. Buenos Aires: Huarpes, 1946.

O’Neill, Chales E., Domínguez, Joaquín María, Diccionario Histórico de la Compañía de Jesús. BiográficoTemático. Madrid: Universidad Pontificia de Comillas, T.1, 2001.

Page, Carlos A., La manzana jesuítica de la ciudad de Córdoba. Córdoba: Municipalidad de Córdoba y Universidad Nacional de Córdoba, 1999.

Page, Carlos A., El Colegio Máximo de Córdoba (Argentina) según las Cartas Anuas de la Compañia de Jesús. Córdoba: BR Copias, 2004.

Arch. esp. arte, LXXXVII, 347, JULIO-SEPTIEMBRE 2014, 245-262

ISSN: 0004-0428, eISSN: 1988-8511, doi: 10.3989/aearte.2014.16 
Page, Carlos A., Los viajes de Europa a Buenos Aires según las crónicas de los jesuitas de los siglos XVVy XVIII. Córdoba: Báez ediciones, 2007.

Page, Carlos A., "Dos relaciones inéditas sobre los viajes de Europa a Buenos Aires de los jesuitas Juan de Viana (1616) y Gaspar García”, en Revista de la Junta Provincial de Historia de Córdoba, N. . 25, Córdoba, 2008.

Page, Carlos A., "El primer intento en defensa del patrimonio jesuítico o una excusa para extirpar su memoria. El expediente sobre la demolición de la iglesia jesuítica de Asunción", en Revista Historia. Vol. 15, N. ${ }^{\circ}$ 2, Brasil: Universidade do Vale do Rio dos Sinos, Unidade Académica de Pesquisa e Pós-Graduacão, 2011a.

Page, Carlos A., "La cubierta y pinturas de la iglesia de la Compañía de Jesús de la ciudad de Córdoba (Argentina)", en Artigrama. N. ${ }^{\circ}$ 26. Departamento de Historia del Arte de la Universidad de Zaragoza, $2011 b$.

Page, Carlos A., Siete Ángeles. Jesuitas en las reducciones y colegios de la antigua provincia del Paraguay, Buenos Aires: Sb ediciones, 2011c.

Page, Carlos A., El Noviciado de Córdoba de la Provincia Jesuitica del Paraguay. Historia y recuperación arqueológica 1607-1990. Córdoba: CIECS-CONICET y Báez Ediciones, 2013a.

Page, Carlos A., "Las cartas de los generales Tirso González y Miguel Ángel Tamburini para la provincia del Paraguay", en IHS. Antiguos jesuitas en Iberoamérica. Vol. 1 N. ${ }^{\circ}$ 1, Córdoba: CIECS-CONICET y UNC, 2013 b.

Pastells SJ, Pablo, Historia de la Compaña de Jesús de la provincia del Paraguay... según los documentos del Archivo General de Indias. Tomo IV. Madrid: Librera General de Victoriano Suárez, 1923.

Ryneš, Václav, "Los jesuitas bohémicos trabajando en las misiones de América Latina después de 1620”, en Ibero-Americana Pragensia, Año V, Praga: Universidad Carolina Praga, 1971.

Sepp SJ, Antonio, Jardín de flores paracuario. Edición crítica de las obras del padre Antonio Sepp SJ misionero en la Argentina desde 1691 hasta 1733 a cargo de Werner Hoffman. Tomo III. Buenos Aires: Eudeba, 1974.

Sierra, Vicente D., Los jesuitas germanos en la conquista espiritual de Hispano-América. Siglos XVII-XVIII. Buenos Aires: Facultad de Filosofía y Teología, 1941.

Solá, Miguel. Augspur, Jorge, Arquitectura Colonial de Salta. Dibujos de Jorge Augspurg. Buenos Aires: Talleres Casa Jacobo Peuser, 1926.

Stěpánek, Pavel, “Juan Kraus de Pilsen: Arquitecto en Argentina y Paraguay”, en Ibero-Americana Pragensis, Año XIII, Praga, 1979.

Stěpánek, Pavel, "Arquitectos de Bohemia activos en América Latina: el caso de Juan Kraus, de Pilsen /Plzeñ”, en Atti, I, Simposio Internazionale del Barocco Latinoamericano. Roma, 1982.

Stěpánek, Pavel, "Simón de Castro - Šimon Boruhradský, un arquitecto checo del siglo XVII en México", en Cuadernos de arte colonial. mayo 1987, č. 2. Madrid, 1987.

Stěpánek, Pavel, "El Misionero Checo Miguel Sabel y el comercio del cristal en Bohemia en América: sus posibles consecuencias iconográficas", en Anales del Museo de América. ‥ ․ 8. Madrid, 2000.

Storni S.J., Hugo, Catálogo de los Jesuitas de la Provincia del Paraguay (cuenca del Plata) 1585-1767. Roma: Institutum Historicum S.I., 1980.

Schuster, Rainer, Michael Wening und seine "Historico-Topographica Descriptio" Ober- und Niederbayerns: Voraussetzungen und Entstehungsgeschichte. München: Uni-Druck, 1999.

Sustersic, Bozidar D., Templos Jesuitico-Guaranies. Buenos Aires: Facultad de Filosofía y Letras de la Universidad de Buenos Aires, 1999.

Techo SJ, Nicolás del, Orosz, Ladislao, Decades virorum illustrium Paraquariae Societatis Jesu. Ex Historia ejusdem Provinciae, et aliunde depromtae... Tyrnavia: Typis Academicis Societatis Jesu, 1759.

Wernicke, Edmundo, "Una carta del P. Antonio Sepp con motivo de la muerte del hermano Juan Krauss, constructor del templo de San Ignacio, en Buenos Aires (1714)", en Anuario de Historia Argentina. Buenos Aires: Domingo Viau y Cía, 1940.

Fecha de recepción: 24-II-2013

Fecha de aceptación: 11-6-2013 